\title{
On the Value of River Network Information in Regional Frequency Analysis
}

\author{
Kichul Jung, ${ }^{\text {a }}$ TAha B. M. J. OuARda, ${ }^{\text {b And Prashanth R. MARPU }}{ }^{\mathrm{c}}$

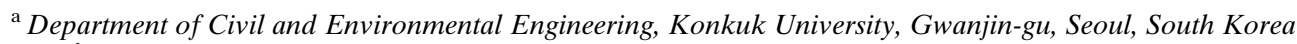 \\ ${ }^{\mathrm{b}}$ Canada Research Chair in Statistical Hydro-Climatology, INRS-ETE, Quebec, Quebec, Canada \\ ${ }^{\mathrm{c}}$ Department of Electrical Engineering and Computer Science, Khalifa University, Masdar City, Abu Dhabi, United Arab Emirates
}

(Manuscript received 22 February 2020, in final form 18 September 2020)

\begin{abstract}
Regional frequency analysis (RFA) is widely used in the design of hydraulic structures at locations where streamflow records are not available. RFA estimates depend on the precise delineation of homogenous regions for accurate information transfer. This study proposes new physiographical variables based on river network features and tests their potential to improve the accuracy of hydrological feature estimates. Information about river network types is used both in the definition of homogenous regions and in the estimation process. Data from 105 river basins in arid and semiarid regions of the United States were used in our analysis. Artificial neural network ensemble models and canonical correlation analysis were used to produce flood quantile estimates, which were validated through tenfold cross and jackknife validations. We conducted analysis for model performance based on statistical indices, such as the Nash-Sutcliffe efficiency, root-meansquare error, relative root-mean-square error, mean absolute error, and relative mean bias. Among various combinations of variables, a model with 10 variables produced the best performance. Further, 49, 36, and 20 river networks in the 105 basins were classified as dendritic, pinnate, and trellis networks, respectively. The model with river network classification for the homogenous regions appeared to provide a superior performance compared with a model without such classification. The results indicated that including our proposed combination of variables could improve the accuracy of RFA flood estimates with the classification of the network types. This finding has considerable implications for hydraulic structure design.
\end{abstract}

KEYWORDS: Hydrology; Statistical techniques; Hydrologic models; Neural networks; Regional models; Flood events

\section{Introduction}

Regional hydrological frequency analysis (RFA) is adopted widely for estimating extreme hydrological events and is essential for the design and operation of hydraulic structures. RFA is usually carried out to transfer information from locations where data are available to ungauged locations (Durrans and Tomic 1996; Chebana and Ouarda 2007) or to partially gauged sites (Seidou et al. 2006). RFA generally consists of two steps, namely, the delineation of groups of hydrologically homogeneous basins called "homogenous regions" or "homogenous neighborhoods," and the transfer of hydrological information within the defined groups. The quality of the final estimate depends mainly on the quality of the defined homogeneous regions. When the region is extremely small, it could have a high level of homogeneity but insufficient information content to transfer the knowledge to the ungauged site. For instance, even a simple transfer through regression requires an adequate number of sites within the region, as adequate regression cannot be built with a small number of points. On the other hand, if the region is extremely large, the amount of information remains important, but the level of homogeneity is reduced substantially. Therefore, a delicate trade-off is usually sought between the amount of information and the homogeneity level. The precise identification of homogenous regions significantly affects the performance of hydrological estimation models (Chebana and Ouarda 2008; Wazneh et al. 2016).

Several methods have been proposed to delineate homogeneous regions. For instance, Matalas et al. (1975) and Beable

Corresponding author: Kichul Jung, jkichul11@naver.com and McKerchar (1982) used geographic and administrative boundaries, Hosking and Wallis (1997) proposed hierarchical clustering using Ward's method (Ward 1963), and Ouarda et al. (2001) recommended using canonical correlation analysis (CCA) to determine hydrological neighborhoods to improve the estimation of flood quantiles. Durocher et al. (2016) analyzed the delineation of homogenous regions based on reference variables representing nonlinear relationships among hydrological data. Abdi et al. (2017a) used the growing neural gas network to determine hydrological data clustering in RFA.

Various physiographical and meteorological variables have been employed to define homogeneous regions in RFA, such as basin area, mean basin slope, main channel length, percentage of area covered by forest, percentage of area covered by lakes, main channel slope, annual mean precipitation, annual mean days with temperature exceeding $0^{\circ} \mathrm{C}$, and curve number $(\mathrm{CN})$ (Flavell 1983; Shu and Ouarda 2007; Aziz et al. 2014; Requena et al. 2018). In the literature on hydrological frequency analysis, the focus is mainly on the development and assessment of new methods of delineation and estimation to enhance hydrological quantile estimation (Castellarin et al. 2001; Ouarda et al. 2008). However, the physiographical and meteorological variables used in RFA have not evolved much in recent decades. Noteworthy gains could result from the integration of drainage network features as new variables in group delineation and regional transfer models, as the characterization of river networks depends on climatic, physiographic, and topographic constraints (Horton 1945; Daniel 1981; Burbank 1992), and flood dynamics are correlated with the drainage density of a basin (Pallard et al. 2009). Information on river network types and their properties is highly relevant to understanding regional hydrological dynamics, such as flood 
response time and the shape of hydrographs, for the generation of flood quantile estimates. Therefore, integrating such information should improve the definition of homogenous regions and significantly affect RFA results.

Several methods have been proposed for estimation using RFA. For instance, several countries have adopted the index flood method (Dalrymple 1960; Hosking and Wallis 1993; Chebana and Ouarda 2009; Kjeldsen and Jones 2010). The key assumption of this approach is that, except for an index factor, flood data from different locations have similar distributions (Dalrymple 1960). Alternatively, the rational method has been used for flood estimates in small river basins (Hua et al. 2003). The rational method is used generally for flood estimation in small urban or rural areas, and it often fails to reproduce specific flood events when actual rainfall data are applied. Diverse regression-based approaches have also been applied in regional estimation (Haddad and Rahman 2012; Ouarda et al. 2018). Hydrological processes generally represent nonlinear behaviors by showing substantial spatial and temporal variability, and nonlinear regression approaches provide estimates that are more accurate than linear regression approaches in regional flood frequency analysis (Pandey and Nguyen 1999; Grover et al. 2002). As regards nonlinear modeling, artificial neural networks (ANNs) have been adopted generally in a wide range of hydrological issues, such as rainfall runoff modeling, hydrological forecasting, and flood quantile estimation in regional frequency analysis (Daniell 1991; Muttiah et al. 1997; Govindaraju 2000; Luk et al. 2001; Dawson and Wilby 2001; Shu and Burn 2004; Dawson et al. 2006; Shu and Ouarda 2007; Chokmani et al. 2008; Turan and Yurdusev 2009; Besaw et al. 2010; Aziz et al. 2014). ANN models in RFA can provide the functional relationships between quantiles and physiographical variables, resulting in improved quantile estimation. Furthermore, the integration of canonical correlation analysis and ensemble ANN has been proposed to improve flood quantile estimation (Ouarda et al. 2001; Shu and Ouarda 2007; Alobaidi et al. 2015). In their analysis, Ouarda et al. (2001) proposed a theoretical framework in applying the CCA for RFA.

RFA has been applied extensively in nonarid regions (Abdi et al. 2017b; Requena et al. 2017; Rahman et al. 2018). However, relatively few studies have proposed RFA procedures for arid and semiarid regions, although the design of irrigation and groundwater recharge dams is crucial in such regions. A small country such as the United Arab Emirates, for instance, has more than 130 recharge dams on intermittent rivers (Gonzalez et al. 2016). Zaman et al. (2012) applied RFA in arid regions in Australia, and Farquharson et al. (1992) conducted RFA using flood data from 162 stations in arid regions, including northwestern Africa, Iran, and Saudi Arabia. However, RFA methods for arid and semiarid regions of the United States have not been developed, and no studies have attempted to use specific river network information to produce flood quantile estimates in the context of RFA.

Drainage networks have a distinct appearance in different regions and environments. For instance, a dendritic network is typically tree like, and it develops freely, with tributaries merging at moderately acute angles (Howard 1967). A parallel network has a parallel form, and it generally develops on large surface slopes characterized by straight main channels and tributaries that join at acute junction angles (Mosley 1972; Phillips and Schumm 1987; Jung et al. 2011). A pinnate network features a feather-like form, with straight major channels and many small tributaries merging at extremely acute junction angles (Howard 1967). A rectangular network involves stream course irregularities characterized by a large number of $90^{\circ}$ bends and tributaries that join at right angles (Howard 1967). A trellis network appears lattice like and has small, short channels that merge at nearly $90^{\circ}$ angles (Howard 1967; Abrahams and Flint 1983). Figure 1 shows examples of the five types of river networks from U.S. basins.

Several attempts have been made to identify different drainage network types based on river network characteristics and propose classification methods. Argialas et al. (1988) used third-order networks digitized from aerial photos to propose a river classification system. Ichoku and Chorowicz (1994) proposed a quantitative approach to determine different river networks based on 14 features of drainage networks derived from digital elevation models (DEMs). Mejia and Niemann (2008) used three measures, including drainage-area increments along a channel, channel course irregularities, and tributary junction angles to classify different network types. More recently, Jung et al. (2015) proposed identification of drainage network types based on the cumulative distributions of secondary tributary lengths within various ranges of tributary junction angles. As different river network types involve specific drainage network features, river network classification should provide valuable information for use in RFA.

The objective of the present work is to develop the RFA model employing the river network information used for delineating the homogenous regions. Further, the optimal combination of physiographical and meteorological variables for flood quantile estimation was analyzed based on statistical indices. As regards the statistical indices, the $k$-fold crossvalidation and jackknife approaches were used to evaluate the accuracy and performance and to present the appropriate model. The $k$-fold cross-validation and jackknife techniques are used extensively to evaluate the prediction model in frequency analysis (Shu and Ouarda 2007; Ouarda and Shu 2009; Alobaidi et al. 2015; Faridzad et al. 2018; Requena et al. 2018; Jung et al. 2019). We applied a machine learning technique, ANN, to produce flood quantile estimates in the RFA procedure at arid and semiarid areas of the United States. As the present study focuses on arid and semiarid regions, we concentrated on intermittent streams, which are normally dry but do flow occasionally and seasonally. The homogenous regions were defined by river network classification, and several statistical indices were used to evaluate the model performance. Based on this analysis, we were able to determine an appropriate combination of variables to improve the performance. It appears that employing river network classification has potential for enhancing the RFA process.

\section{Materials and methods}

\section{a. Dataset}

A dataset representing 105 river basins, dominated by intermittent streams in arid and semiarid regions of the United States, was developed for RFA. The spatial distribution of the 
A)

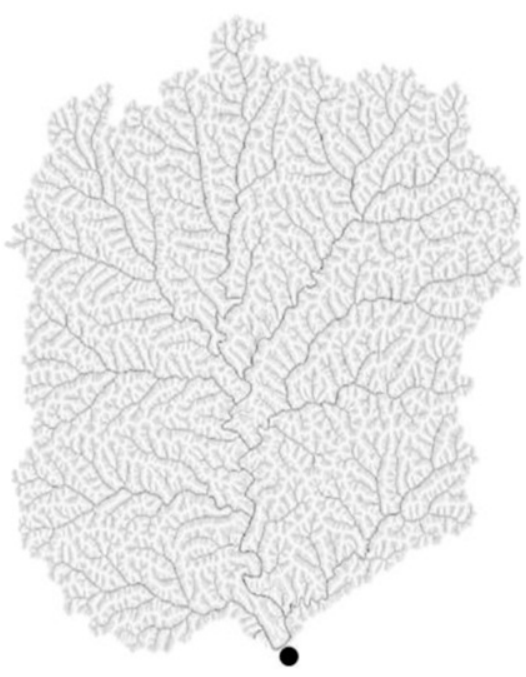

D)

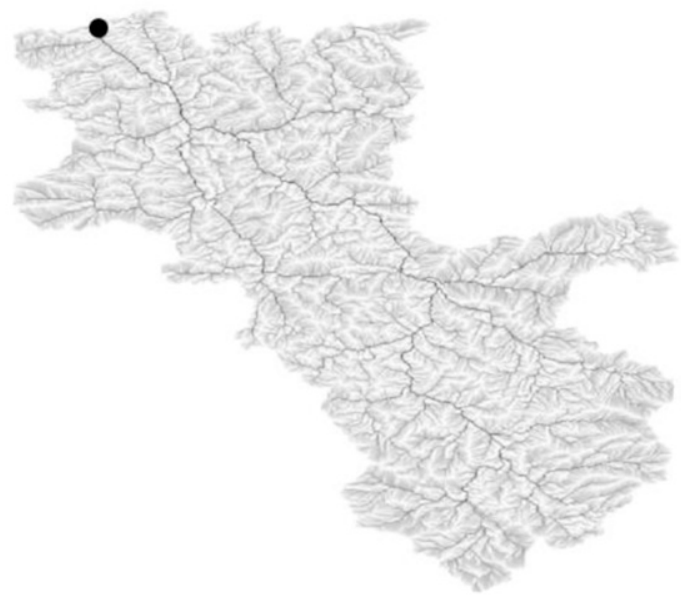

B)

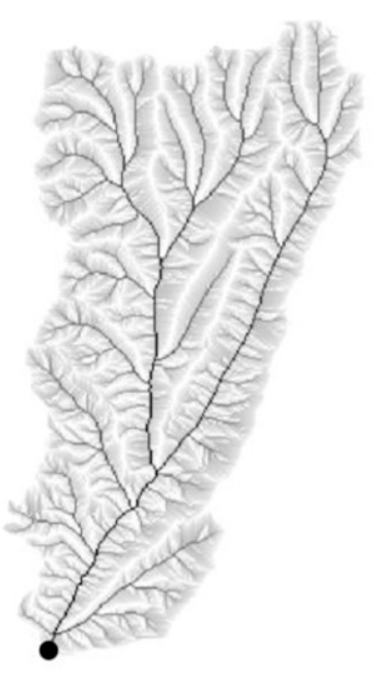

C)

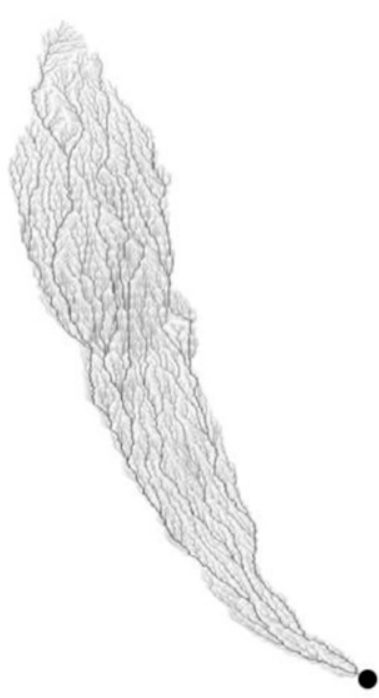

E)

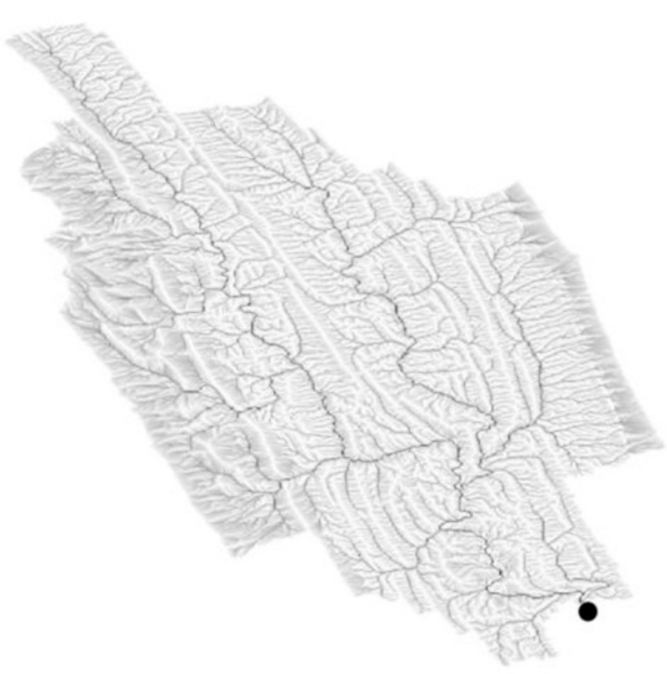

FIG. 1. Illustrations for five drainage networks: (a) Buckeye Run, WV, for a dendritic network; (b) Yellow Creek, CO, for a parallel network; (c) Paisano Wash, AZ, for a pinnate network; (d) Boreas River, NY, for a rectangular network; and (e) Sleepy Creek, WV, for a trellis network. The block point of each network type indicates the outlet of the river basin, and the lines indicate the channels in the basin.

relevant stations is presented in Fig. 2. These 105 stations were selected among the hydrological stations on intermittent streams in the United States to ensure the quality of the dataset based on the following criteria:

1) availability of an historical flow record of at least 15 years to ensure reliable quantile estimates;

2) basin characterized by a natural flow regime;

3) the historical flow data at all retained gauging stations had to pass the tests of homogeneity (Wilcoxon 1945), stationarity (Kendall 1948), and independence (Wald and Wolfowitz
1943), which permit verifying existence from an autocorrelation of significant first-order in the observations.

Several physiographical and meteorological variables were estimated and employed in our analysis. The first seven variables (7Var) included in the database have been used generally in previous studies (Ouarda et al. 2001; Shu and Ouarda 2007; Mosaffaie 2015). These include drainage area (AREA), length of the main channel (LMC), slope of the main channel (SMC), mean basin slope (MBS), curve number (CN), annual mean precipitation (AMP), and annual mean temperature (AMT). 


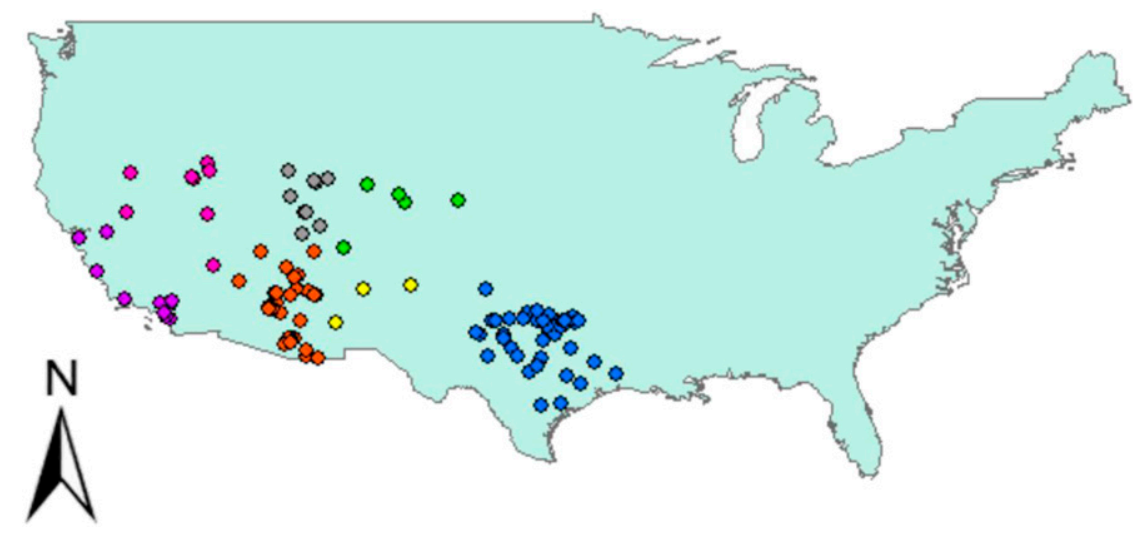

FIG. 2. Locations of 105 stations in the United States. Dots in the figure indicate stations in different states: red dots in Arizona, purple ones in California, green ones in Colorado, pink ones in Nevada, yellow ones in New Mexico, blue ones in Texas, and gray ones in Utah.

New physio-meteorological variables were added, including the aridity index (ADI), tributary junction angle (TJA), time of concentration $\left(T_{c}\right)$, and three power-law exponents (3EXP) in an attempt to improve regional hydrological estimates. Details on the new variables are provided in section 2c. Descriptive statistics for all physio-meteorological variables used in the present study are presented in Table 1.

Ten-year (q10), 50-year (q50), and 100-year (q100) specific quantiles were considered as hydrological variables. They were estimated using the flow records from all the gauged sites in the study area. The following statistical distributions were considered in the fitting processes: gamma, generalized extreme value, generalized Pareto, Gumbel, two-parameter lognormal, threeparameter lognormal, log-Pearson type III, Pearson type III, and Weibull. At each station, the Bayesian information criterion was used to identify the optimal statistical distribution to fit the data. The physiographical, meteorological, and hydrological variables were transformed to achieve normality and standardized to obtain consistent format. Subsequently, the transformed variables were applied to the model for flood quantile estimation.

\section{b. CCA and ANN ensemble model}

In this study, the CCA and ANN ensemble techniques (EANN-CCA) were integrated to estimate the flood quantiles at ungauged locations. Shu and Ouarda (2007) suggested the EANN-CCA model and demonstrated that its estimation performance was superior compared with that of other generally used RFA models. We used the EANN-CCA model to obtain flood quantile estimates in arid and semiarid regions. In this model, CCA was used to construct a transformed physio-meteorological space based on site characteristics. The canonical variables derived from CCA were fed to an ANN ensemble model to obtain flood quantile estimates. A brief description of the CCA and ANN ensembles is provided in sections $2 \mathrm{~b}(1)$ and $2 \mathrm{~b}(2)$, respectively.

\section{1) CANONiCAL CORRELATION ANALYSIS}

The CCA approach represents a statistical multivariate analysis, and it characterizes the relationship between two sets of random variables, removing nonessential data and preserving the original property of the variables. In CCA procedures, $X$ indicates a set of physiographical and meteorological variables, and $Y$ represents a set of hydrological variables. These physiographical and meteorological variables can be obtained easily for ungauged locations. Given two sets ( $X$ and $Y$ ) of random variables, the CCA approach was applied to link the sets using vectors of canonical variables that were linear combinations of the original ones. When linear combinations of $X$ and $Y$ are denoted as $W$ and $V$, the equations are

$$
\begin{gathered}
W=\alpha^{\prime} X, \\
V=\beta^{\prime} Y,
\end{gathered}
$$

where $W$ implies the canonical variables for the physiographical and meteorological variables, and $V$ indicates the canonical variables for the hydrological variables. The correlation of the two canonical variables is

$$
\rho=\frac{\alpha^{\prime} \sum_{X Y} \beta}{\sqrt{\alpha^{\prime} \sum_{X} \alpha} \sqrt{\beta^{\prime} \sum_{Y} \beta}} .
$$

TABLE 1. Descriptive statistics of 13 variables for physiographical and meteorological features used for regional frequency analysis.

\begin{tabular}{lcccc}
\hline \hline \multicolumn{1}{c}{ Variables } & Min & Max & Mean & Std dev \\
\hline AREA $\left(\mathrm{km}^{2}\right)$ & 17.787 & 21000.57 & 1483.295 & 3179.978 \\
LMC $(\mathrm{km})$ & 8.277 & 435.794 & 73.641 & 74.662 \\
SMC $(\%)$ & 0.095 & 13.617 & 2.057 & 2.551 \\
MBS $(\%)$ & 0.775 & 57.616 & 14.797 & 13.67 \\
CN & 60.509 & 85.500 & 75.459 & 4.86 \\
AMP $(\mathrm{mm})$ & 28.617 & 232.156 & 99.113 & 44.211 \\
AMT $\left({ }^{\circ} \mathrm{C}\right)$ & 1.51 & 21.242 & 14.106 & 4.824 \\
ADI & 0.146 & 2.98 & 0.792 & 0.377 \\
TJA $\left({ }^{\circ}\right)$ & 41.62 & 71.485 & 55.66 & 5.729 \\
$T_{c}(\mathrm{~h})$ & 1.212 & 194.372 & 19.658 & 27.274 \\
q10 $\left(\mathrm{m}^{3} \mathrm{~s}^{-1} \mathrm{~km}^{-1}\right)$ & 62.284 & 15644 & 3102.38 & 3537.667 \\
q50 $\left(\mathrm{m}^{3} \mathrm{~s}^{-1} \mathrm{~km}^{-1}\right)$ & 96.476 & 54352 & 6432.242 & 8244.12 \\
q100 $\left(\mathrm{m}^{3} \mathrm{~s}^{-1} \mathrm{~km}^{-1}\right)$ & 109.246 & 86402 & 8557.539 & 11967.96 \\
\hline
\end{tabular}


The vectors of $\alpha$ and $\beta$ can be determined by maximizing the correlation. The CCA in the EANN-CCA model allows the construction of a transformed physiographical space, called the canonical space, defined by physiographical and meteorological variables. The constructed model can establish a functional relationship between the canonical physiographical and meteorological variables on one side and the canonical hydrological variables on the other. Based on the functional relationship, estimates of the hydrological variables at ungauged locations can be obtained in the canonical space. More theoretical information about the use of CCA in RFA is presented in Ouarda et al. (2001).

\section{2) ANN ENSEMBLE}

In the Shu and Ouarda (2007) model, the physiographical and meteorological variables are first projected into the canonical space and then fed to an ANN model to estimate hydrological variables at ungauged locations (Dawson et al. 2006). In RFA, ANNs can be used as nonlinear hydrological models to approximate the functional relationship between the canonical physio-meteorological variables and the hydrological variables.

Using the variables, multilayer perceptrons (MLPs), consisting of an input layer, hidden layers, and an output layer, were utilized to train the hydrological variables. A network with MLPs was trained based on samples obtained from gauged stations for estimating the hydrological variables, such as flood quantiles. In the training process, network parameters were optimized until the estimation error was minimized, and the network obtained the specified level of accuracy. The Levenberg-Marquardt (LM) algorithm (Hagan and Menhaj 1994) was used to identify optimal solutions and minimize the network error in the study. Further, early stopping criteria were used to avoid overfitting issues in ANN training. Once the ANN model completed the training procedure, the output layer provided an ANN prediction, i.e., the flood quantile estimates in the present work.

To enhance the generalization ability and stability of a single ANN, several researchers have used an ANN ensemble model based on multiple ANNs trained and produced by individual networks (Cannon and Whitfield 2002; Dietterich 1997). Among ANN ensemble methods, the bagging procedure has been used to produce a unique ensemble output, i.e., the flood quantile estimate, by averaging the networks. In the process, each ANN member of the ensemble was trained independently on a subset of the training set, sampled with a replacement of the dataset. This is a simple and effective approach to generate ensemble output. Detailed information on the use of the bagging method in RFA is available in Shu and Ouarda (2007).

\section{c. Estimation of new physiographical variables}

We proposed and tested new variables that had not been used previously in RFA to assess whether using them would improve the performance of RFA models. These variables are related to the hydrological and geomorphological dynamics of a river basin, including tributary junction angles, time of concentration, aridity index, and three exponents used for river network classification. The procedures to obtain the proposed variables are described in sections $2 c(1)-2 c(4)$.

\section{1) TRIBUTARY JUNCTION ANGLE}

Drainage networks generally display quite distinct features in different regions, depending on the regional and local lithologic and tectonic conditions during the development of the network (Parvis 1950; Cox 1989; Burbank 1992). River network characteristics have a significant effect on hydrological responses. Among other river network properties, tributary junction angles have been investigated frequently to understand variations in the angles among different river network types (Abrahams and Flint 1983; Phillips and Schumm 1987; Ichoku and Chorowicz 1994; Hackney and Carling 2011).

Tributary junction angles are used also in RFA to estimate flood quantiles along with other physiographic and climatic variables. Tributary junction angles are important features in a basin and are calculated at every junction between primary and secondary tributaries (Mejia and Niemann 2008; Jung et al. 2015). A primary tributary is calculated using the chord between the junction and a location determined based on the Euclidean distance upstream from the junction on the larger tributary in a river network. A secondary tributary is estimated using the chord between the junction and a location determined based on the Euclidean distance upstream from the junction on the smaller tributary in the river network. Subsequently, the two chords can be applied to obtain the junction angles. Comprehensive theoretical information on calculating the angles is presented in the studies of Mejia and Niemann (2008) and Jung et al. (2015).

\section{2) TIME OF CONCENTRATION}

The time of concentration $T_{c}$ is defined as the time required for runoff to travel from the most hydraulically distant location in a basin to its outlet (Jung et al. 2017). As a crucial variable linked directly to a river basin hydrological regime, $T_{c}$ was included as an RFA variable in the present study. Several researchers have alluded to its importance by investigating $T_{c}$ for diverse hydrological applications. Wong (2005) and Sharifi and Hosseini (2011) used $T_{c}$ to estimate the peak discharge for the construction of hydraulic structures. In a more recent study, Jung et al. (2017) examined $T_{c}$ within different river network types to identify whether network types affect the hydrological response of a basin.

Several $T_{c}$ estimation methods have been proposed. We used the lag method of the Natural Resources Conservation Service (NRCS) (U.S. Department of Agriculture). Folmar and Miller (2000) demonstrated the effectiveness of this method for computing $T_{c}$, and Jung et al. (2017) examined $T_{c}$ values calculated using the NRCS lag method alongside drainage network characteristics for use in hydrological models. In the NRCS lag method, $T_{c}$ can be estimated by

$$
T_{c}=\frac{L}{0.6},
$$

where $L$ is the watershed lag (h) defined as a function of the hydraulic length. This lag can be calculated as 


$$
L=\frac{l^{0.8}(S+1)^{0.7}}{1900 Y^{0.5}}
$$

where $Y$ represents the mean basin slope (\%) and $l$ indicates the main channel length ( $\mathrm{ft}$ ). The unit of the main channel length is converted from $\mathrm{km}$ to $\mathrm{ft}$ for application of the equation. The variable $S$ represents the maximum potential retention related to the rate of infiltration at the soil surface in the basin. The maximum potential retention can be written as

$$
S=\left(\frac{1000}{\mathrm{CN}}\right)-10,
$$

where $\mathrm{CN}$ is the curve number. Soils show high infiltration rates when the $\mathrm{CN}$ value is low and low infiltration rates when the $\mathrm{CN}$ is high. Note that $T_{c}$ can be obtained at ungauged locations and can serve as a physiographical variable in RFA flood quantile estimates.

\section{3) ARIDITY INDEX}

We used an ADI, which is a numerical indicator of the degree of dryness of a climate, as a meteorological variable in the study of RFA. Walton (1969) investigated the nature and causes of aridity, which are affected generally by geomorphological processes, vegetation, and climatic phenomena, including seasonality. For example, the rain shadow effect, which is related to topographical features, is an important factor that leads to aridity. The rain shadow effect occurs when rising air at the windward sides of mountain ranges cools by generating precipitation and losing moisture, while descending air on the leeward side of ranges warms up, thereby creating arid environments. Stadler (1987) and Maliva and Missimer (2012) employed ADI to identify aridity patterns and conditions correlated with climate variables, such as temperature, precipitation, and evaporation for water resource estimation and management.

A low ADI value implies an arid environment, whereas a large value indicates a humid environment. We investigated whether ADI could be used as a climate index to improve flood quantile estimates in arid and semiarid regions. ADI can be estimated as follows:

$$
\mathrm{ADI}=\frac{P}{\mathrm{PET}},
$$

where $P$ is the annual mean precipitation (over ranges of 10 70 years) and PET is potential evapotranspiration. We used the Hamon potential evapotranspiration equation, which has been employed in global hydrological studies to estimate potential evapotranspiration in our study (Hamon 1960). The monthly PET $\left(\mathrm{mm} \mathrm{month}{ }^{-1}\right.$ ) equation based on Hamon's method is as follows:

$$
\mathrm{PET}=13.97 \times d \times D^{2} \times W_{t},
$$

where $d$ is the number of days in the month, and $D$ is the mean monthly number of hours of daylight in 12-h units. The variable $W_{t}\left(\mathrm{~g} \mathrm{~m}^{-3}\right)$ is a saturated water vapor density term estimated by

$$
W_{t}=\frac{4.95 \times e^{0.062 \times T}}{100},
$$

where $T$ is the mean monthly temperature $\left({ }^{\circ} \mathrm{C}\right)$.

Further, the Hamon equation for the annual PET $\left(\mathrm{mm} \mathrm{yr}^{-1}\right)$ is as follows:

$$
\mathrm{PET}=[0.5949+(0.1189 \times \mathrm{TC})] \times 365,
$$

where TC is the annual mean temperature $\left({ }^{\circ} \mathrm{C}\right)$. For ADI calculations in the current study, PET was obtained based on Eq. (10) using the annual mean temperature.

\section{4) ClassificAtion OF RIVER NETWORK TYPES}

In several studies, river networks were classified based on the network characteristics (Ichoku and Chorowicz 1994; Mejia and Niemann 2008; Jung et al. 2015). The development and characterization of drainage networks normally depend on local and regional constraints (Parvis 1950; Howard 1967). We used methodology proposed by Jung et al. (2015) to classify river networks into five types (dendritic, parallel, pinnate, rectangular, and trellis) in arid and semiarid regions. This method was selected for its simplicity, as only two characteristics, namely, tributary junction angles and secondary tributary lengths in a basin are required to distinguish between different river network types. This approach was used to provide data for defining homogenous neighborhoods based on the river network classification in RFA.

To examine the classification of the river networks, the tributary junction angles of a basin are grouped into three overlapping ranges $\left(0^{\circ}-60^{\circ}, 30^{\circ}-90^{\circ}\right.$, and $\left.60^{\circ}-120^{\circ}\right)$ by considering continuity. Subsequently, the lengths of the secondary tributaries in the basin were estimated for the different ranges, and the distributions of the secondary tributary lengths were obtained to produce cumulative histograms of the length distributions. These cumulative histograms provide three powerlaw exponents for the secondary tributary lengths, which are similar to the fractal dimensions, to classify different river network types (Velde et al. 1990; Gloaguen et al. 2007; Jung et al. 2015). The exponents of the power law can be calculated based on the following equation:

$$
N_{i}=\frac{C}{l_{i}^{D}},
$$

where $D$ implies the power-law exponent, $c$ means the proportional constant, and $N_{i}$ indicates the number of secondary tributaries based on a length less than $l_{i}$. The method for classifying the different networks is described briefly here, and further details on the procedure are presented in Jung et al. (2015). The present study is the first to employ these power-law exponents in the context of RFA. The exponents were assessed to determine whether they could be used as physiographical variables to improve flood quantile estimates.

\section{d. Model validation methods and criteria}

Tenfold cross-validation and jackknife procedures are used regularly as resampling methods to assess the performance of regional frequency models (Miller 1964; Shao and Tu 2012). We used these approaches for model validation and to evaluate the relative performance of the RFA models. Figure 3 shows the construction process of the EANN-CAA model for 


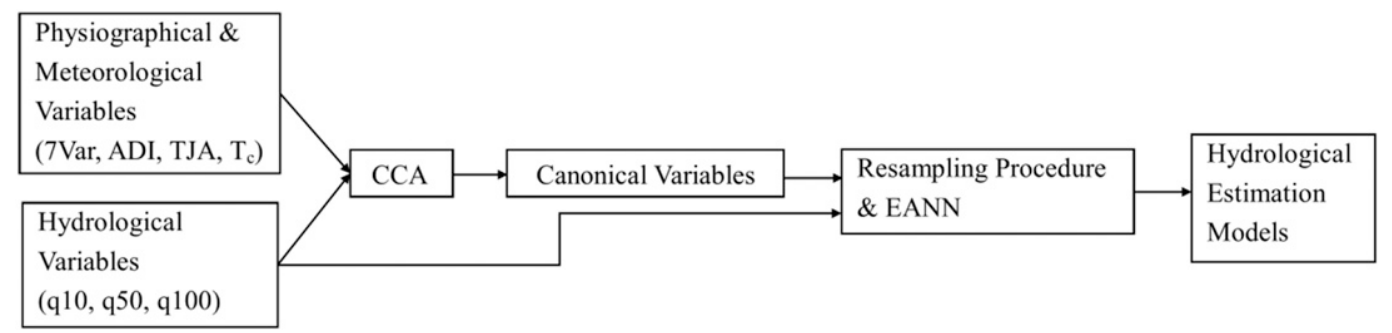

FIG. 3. EANN-CCA model process for regional frequency estimation of hydrological variables.

regional frequency estimation of hydrological variables, along with the resampling procedures.

In tenfold cross-validation, the original sample was divided randomly into ten subsamples of the same size and, in each trial, one of the subsamples was used to test the proposed EANN-CCA model, while the remaining nine subsamples were used as training data. The process of cross validation was repeated 10 times by producing the model outputs based on a dataset of known data. These outputs were then averaged over the rounds to provide an estimate of the model performance.

We also conducted jackknife estimation for three predicted flood quantiles (q10, q50, and q100) using the model involving river network types. In the jackknife procedure, each gauged site in the study area was removed temporarily from the database in every trial and considered as an ungauged location. Subsequently, regional estimates for the site were obtained using an EANN-CCA model that was trained based on the data from the remaining locations. For the model used in this study, various numbers of neurons were tested to identify the optimal number of hidden neurons. Generally, when very few neurons are used, an underfitting problem could arise because of insufficient complexity to produce a functional relationship between input and output systems. On the other hand, when many neurons are used, an overfitting problem could arise because the number of training cases is inadequate. Considering these factors in their analyses, Shu and Ouarda (2007) identified the number of neurons in RFA ranging from three to eight. We also used various numbers of hidden neurons ranging from 2 to 17 in estimating flood quantiles. It was found that fewer than five hidden neurons provided superior estimates. We used five hidden neurons, as proposed by Shu and Ouarda (2007), and an ensemble size of 14, indicating 14 ANN members and averages of the networks to produce a unique output (flood quantile).

The EANN-CCA model used in our study was assessed further using five measures, namely, the Nash-Sutcliffe efficiency (NSE), root-mean-square error (RMSE), relative rootmean-square error (rRMSE), mean absolute error (MAE), and relative mean bias (rBIAS). The five measures are defined by the following equations, respectively:

$$
\mathrm{NSE}=1-\frac{\sum_{i=1}^{n}\left(q_{i}-\hat{q}_{i}\right)^{2}}{\sum_{i=1}^{n}\left(q_{i}-\bar{q}_{i}\right)^{2}},
$$

$$
\begin{aligned}
\mathrm{RMSE} & =\sqrt{\frac{1}{n} \sum_{i=1}^{n}\left(q_{i}-\hat{q}_{i}\right)^{2},} \\
r \mathrm{RMSE} & =100 \times \sqrt{\frac{1}{n} \sum_{i=1}^{n}\left(\frac{q_{i}-\hat{q}_{i}}{q_{i}}\right)^{2}}, \\
\mathrm{MAE} & =\frac{1}{n} \sum_{i=1}^{n}\left|q_{i}-\hat{q}_{i}\right|, \\
r \mathrm{BIAS} & =\frac{100}{n} \sum_{i=1}^{n}\left(\frac{q_{i}-\hat{q}_{i}}{q_{i}}\right),
\end{aligned}
$$

where $n$ indicates the total number of basins used in the analysis, $q_{i}$ represents the at-site estimate for location $i, \bar{q}_{i}$ implies the mean of at-site estimate, and $\hat{q}_{i}$ represents the RFA flood estimate for location $i$.

\section{Results}

\section{a. Models without river network classification assessed via tenfold cross validation}

The proposed EANN-CCA model was applied to the 105 river basins to estimate three flood quantiles corresponding to generally used return periods ( $110, q 50$, and q100). In the analysis, we used the new physiographical and meteorological variables (ADI, TJA, $T_{c}$, and $3 \mathrm{EXP}$ ) related to river network characteristics with the seven variables (7Var) used in previous studies. Based on the collected variables, we examined the flood quantile estimation by considering homogenous regions defined by river network classification. In section $3 \mathrm{a}$, the classification was not applied in estimating the flood quantiles, implying that the definition of the homogenous regions in RFA was not considered. In addition, we investigated whether adding the new variables representing drainage network dynamics could improve quantile estimation. We applied the tenfold cross-validation procedure to this model to validate the model performance. We conducted several case studies using various combinations of variables to identify the parameters that would produce the optimal performance. To ensure generalizability, we examined the sizes of the ensemble in the EANN-CCA model. We found that with an extremely large ensemble, the training time increased, and when it was extremely small, generalizability would be insufficient. We selected an ensemble size of 14 in the EANN-CCA model process, as has been suggested by Shu and Ouarda (2007). 

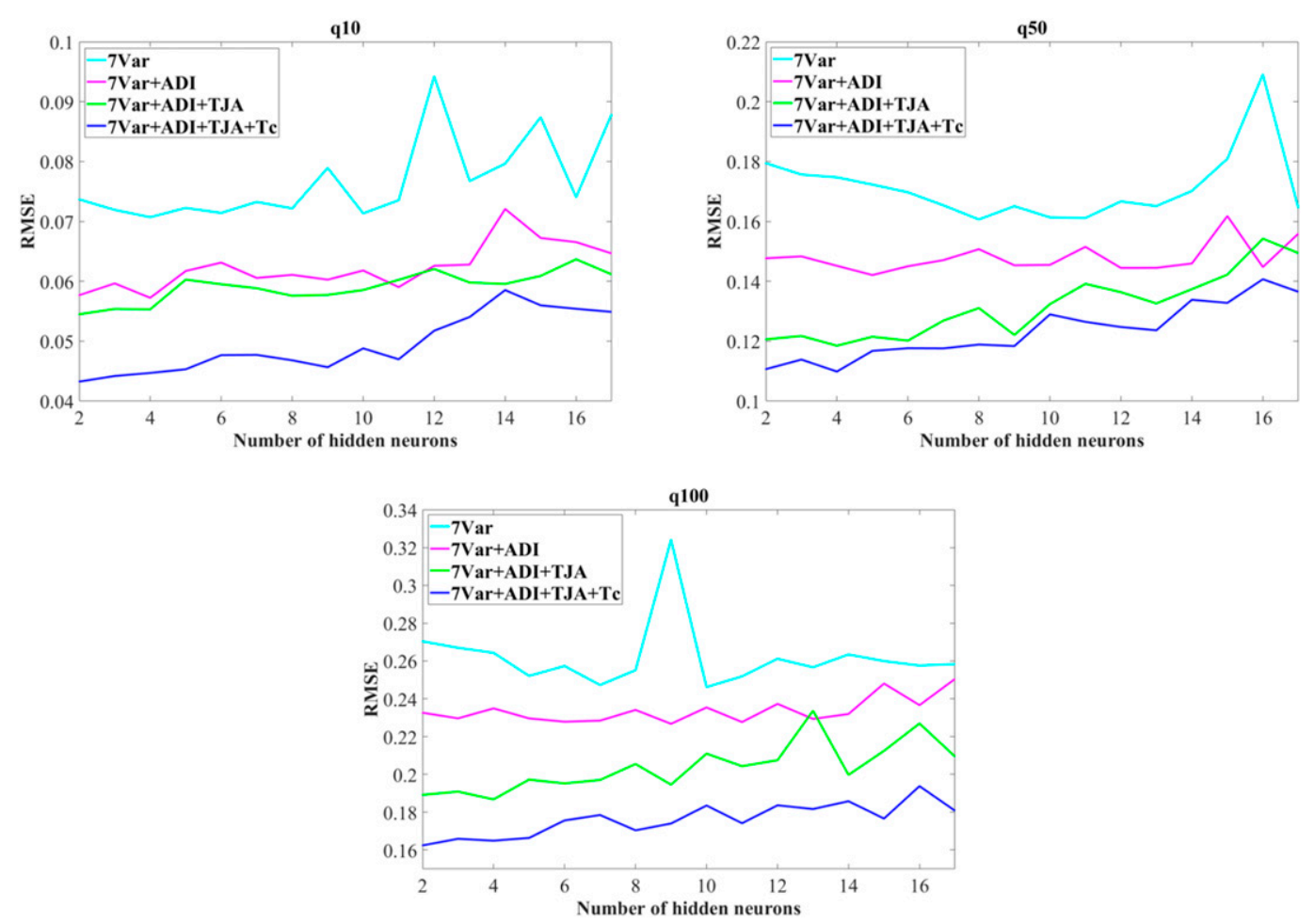

FIG. 4. RMSE of the EANN-CCA model for 105 stations based on the cross-validation method for four case studies (7Var, 7Var + ADI, 7Var + ADI + TJA, 7Var + ADI + TJA $+T_{c}$ ) for the three quantiles with a number of hidden neurons increasing from 2 to 17.

An EANN-CCA model with 10 variables (7Var, ADI, TJA, and $T_{c}$ ) was employed to determine an optimal combination of variables for flood quantile estimates. Figure 4 shows the plot of the RMSE values based on four variable combinations (7Var, 7Var + ADI, 7Var + ADI + TJA, and $7 \mathrm{Var}+\mathrm{ADI}+\mathrm{TJA}+T_{c}$ ) for the three quantiles as a function of the number of hidden neurons (ranging from 2 to 17). The three cases including 7Var, 7Var + ADI, and 7Var + ADI + TJA appeared to produce a superior performance based on a number of neurons ranging from four to six. On the other hand, the RMSE for most input variable combinations $\left(7 \mathrm{Var}+\mathrm{ADI}+\mathrm{TJA}+T_{c}\right)$ tended to increase using more than two neurons.

Figure 4 indicates that the RMSE values decrease gradually when the new variables are included. For example, the EANN-CCA model using 7Var + ADI produced a superior performance compared with the model with 7Var for all quantiles. Further, the model using 7Var + ADI + TJA shows decreased RMSE values, especially for the q50 and q100 quantiles. The model using 7Var $+\mathrm{ADI}+\mathrm{TJA}+T_{c}$, however, showed the optimal performance. The lowest RMSE values of $0.043,0.110$, and 0.163 were achieved for the q10, q50, and q100 quantiles, respectively, using this combination of variables. We found that including the ADI variable improved the model performance. However, high RMSE values and strong fluctuations were observed with large numbers of hidden neurons. This could be ascribed to EANN-CCA models with many hidden neurons having sufficient training cases to properly train all the neurons during the procedure.

We also examined the effect of the $3 \mathrm{EXP}$ variables on the model performance for the three quantiles. The performance of the EANN-CCA model using 7Var + ADI + 3EXP was superior compared with the model with 7Var + ADI. However, when we added the $T_{c}$ variable, there was no improvement in the RMSE values. The behavior of the model using 7Var + ADI + 3EXP + TJA was similar to that of the model using $7 \mathrm{Var}+\mathrm{ADI}+3 \mathrm{EXP}+T_{c}$. The combination $3 \mathrm{EXP}+T_{c}$ or $3 \mathrm{EXP}+\mathrm{TJA}$ did not appear to improve the model performance. Furthermore, the performance of the model using a combination of 7Var + ADI + $\mathrm{TJA}+T_{c}+3 \mathrm{EXP}$ was the worst. The results suggested that the adoption of redundant variables in RFA could lead to unnecessarily complex models that reduce overall model performance.

Further, we investigated combinations of other variables without ADI to determine how such other variables affected model performance. Adding the variables TJA and $T_{c}$ to the model with 7Var led to a gradual improvement in the performance. However, the best RMSE value derived from the model using 7Var + TJA $+T_{c}$ was inferior to the worst RMSE values derived from the model with $7 \mathrm{Var}+\mathrm{ADI}+\mathrm{TJA}+T_{c}$. The performance was achieved with the combination 7Var + $\mathrm{ADI}+\mathrm{TJA}+T_{c}$. The performance of the model with 7Var + $3 \mathrm{EXP}+\mathrm{TJA}+T_{c}$ was similar or inferior to that of the model using 7Var + TJA $+T_{c}$. The performance of the model using 
TABLE 2. Jackknife validation results based on the EANN-CAA model for q10, q50, and q100 quantiles using 105 river basins in arid and semiarid regions. The bold font indicates the best-performing approach for each quantile.

\begin{tabular}{|c|c|c|c|c|c|c|}
\hline & \multicolumn{2}{|r|}{$\mathrm{q} 10$} & \multicolumn{2}{|r|}{ q50 } & \multicolumn{2}{|r|}{ q100 } \\
\hline & 7 Var & $7 \mathrm{Var}+\mathrm{ADI}+\mathrm{TJA}+T_{c}$ & 7 Var & $7 \mathrm{Var}+\mathrm{ADI}+\mathrm{TJA}+T_{c}$ & 7 Var & $7 \mathrm{Var}+\mathrm{ADI}+\mathrm{TJA}+T_{c}$ \\
\hline NSE & 0.513 & 0.628 & 0.491 & 0.546 & 0.434 & 0.452 \\
\hline RMSE & 0.071 & 0.062 & 0.169 & 0.158 & 0.261 & 0.253 \\
\hline rRMSE (\%) & 186.77 & 99.92 & 183.24 & 122.54 & 202.34 & 136.53 \\
\hline MAE & 0.017 & 0.010 & 0.038 & 0.026 & 0.054 & 0.043 \\
\hline rBIAS $(\%)$ & -62.10 & -24.95 & -52.47 & -34.68 & -62.58 & -41.97 \\
\hline
\end{tabular}

$7 \mathrm{Var}+3 \mathrm{EXP}+T_{c}$ appeared to be inferior to that of the model with 7Var + 3EXP.

\section{b. Models without river network classification assessed via jackknife validation}

We evaluated the EANN-CCA model with different combinations of variables for the three quantiles (q10, q50, and q100) using the jackknife validation procedure. The RMSE and rRMSE indices were used to assess the predictive accuracy of the models in absolute and relative terms, and the MAE and rBIAS indices were used to identify eventual overestimation and underestimation of flood quantile estimates. Table 2 shows the evaluation results of the models with 7Var and 7Var + ADI + TJA $+T_{c}$, the model that achieved superior performance in the tenfold cross-validation procedure. The performance of the model with 7Var + ADI + TJA + $T_{c}$ was superior to that of the model with 7Var for the five indices.
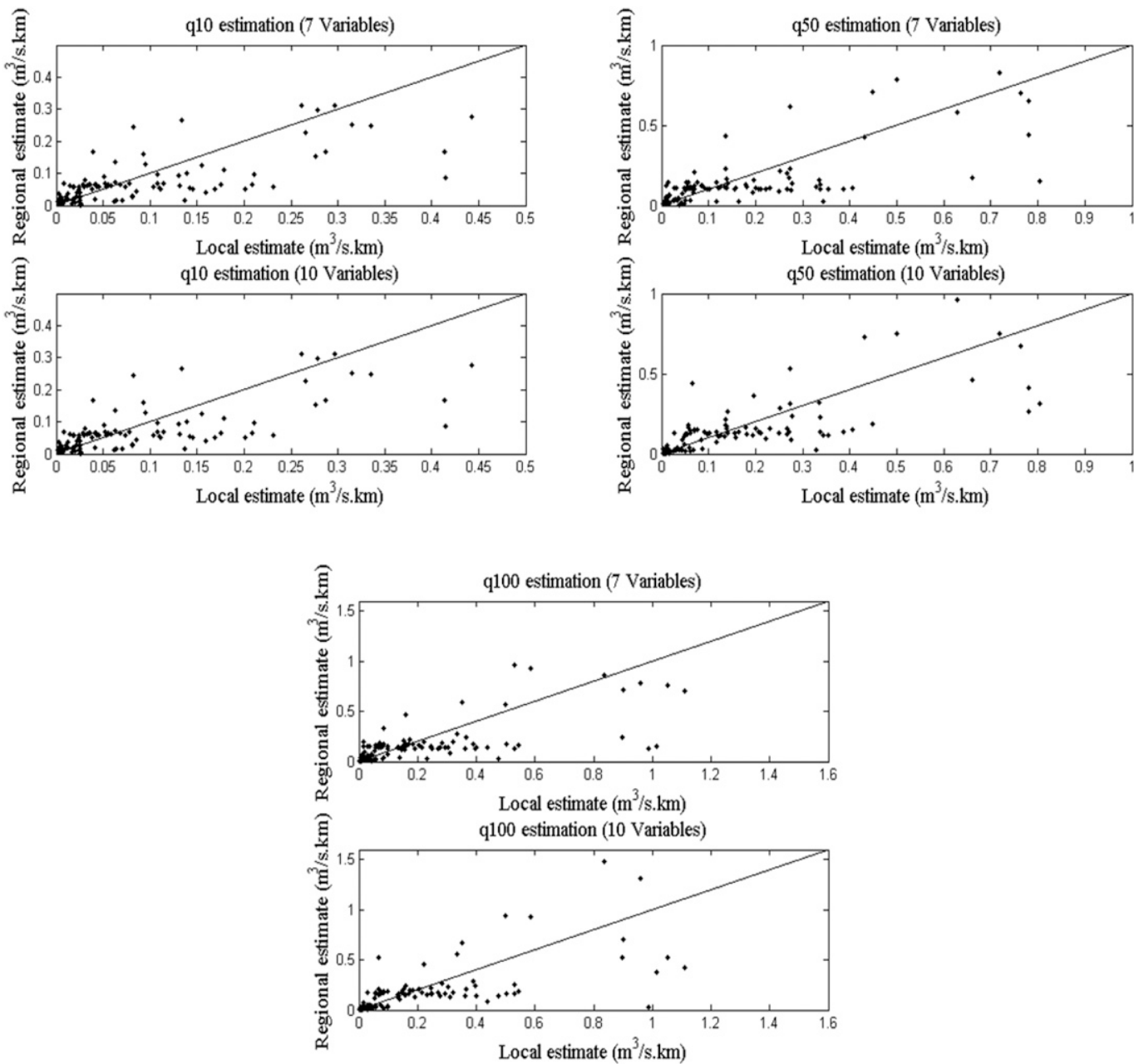

FIG. 5. Jackknife estimation for three quantiles (q10, q50, and q100) using the model with 7Var (7 variables) and the model with $7 \mathrm{Var}+\mathrm{ADI}+\mathrm{TJA}+T_{c}$ (10 variables). 

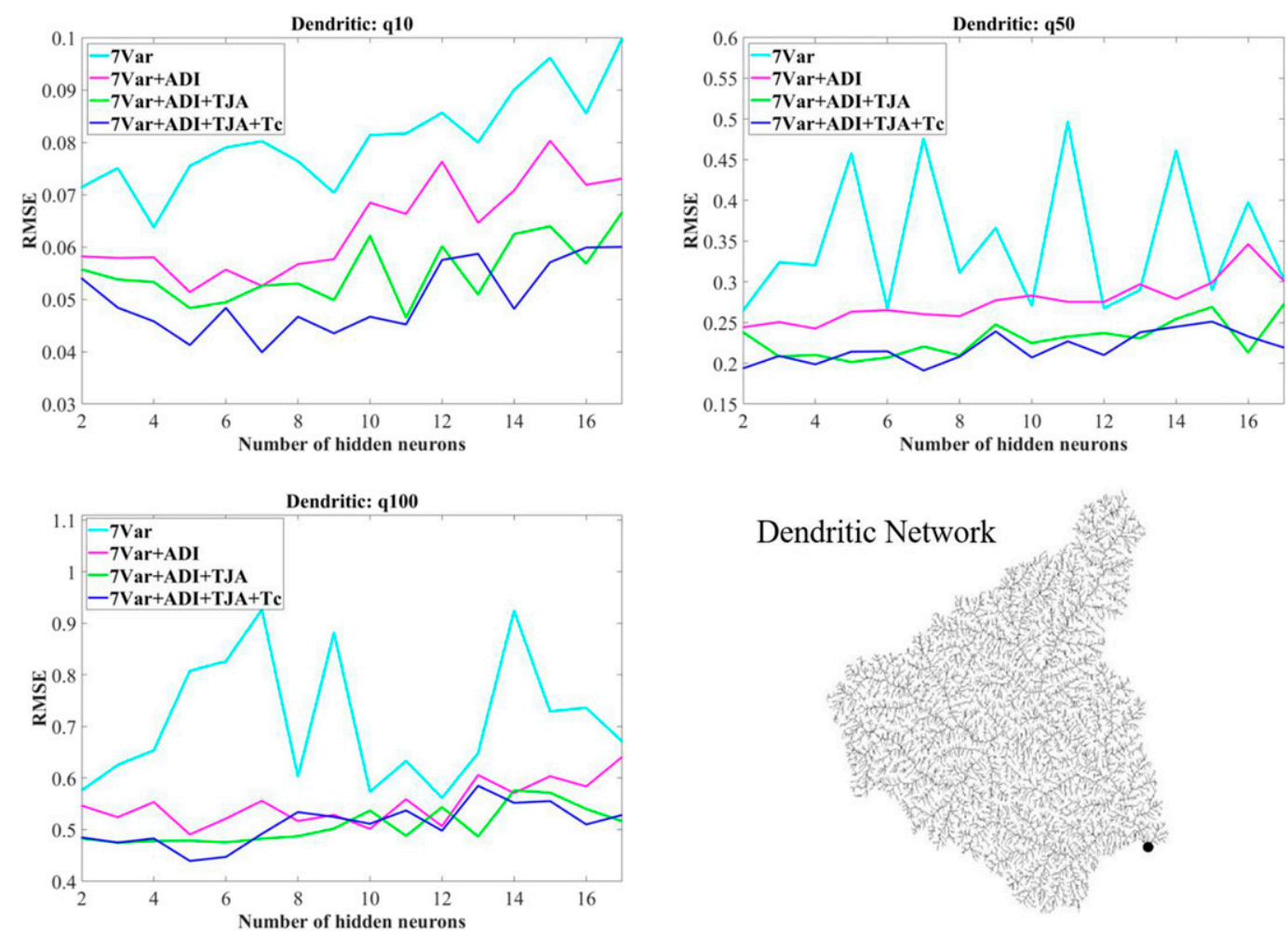

FIG. 6. RMSE of the EANN-CCA model for dendritic networks using the cross-validation method for four case studies (7Var, 7Var + ADI, 7Var + ADI + TJA, 7Var + ADI + TJA + $\left.T_{c}\right)$ for the three quantiles with a number of hidden neurons increasing from 2 to 17.

Figure 5 shows a plot of the regional estimates as a function of the local estimates for all three quantiles, based on the models using 7Var and 7Var + ADI + TJA $+T_{c}$. Regional estimates include those obtained from the proposed model using the jackknife validation technique, whereas local estimates include at-site observations of the quantiles. We determined that the model using $7 \mathrm{Var}+\mathrm{ADI}+\mathrm{TJA}+T_{c}$ provided optimal estimates according to the tenfold cross-validation and jackknife methods and we only plotted the results for these two combinations. Figure 5 shows that the estimation error is reduced for sites with low quantile values. However, the models appear to underestimate these values at sites with high quantile values. This could be ascribed to inadequate training data available in the variable space for the RFA procedures.

Although Fig. 5 appears to show no obvious difference between the results for 7Var and 7Var $+\mathrm{ADI}+\mathrm{TJA}+T_{c}$, the values of the statistical indices including NSE, RMSE, rRMSE, MAE, and rBIAS improved when we used the model with $7 \mathrm{Var}+\mathrm{ADI}+\mathrm{TJA}+T_{c}$. The NSE shows a range from 0.513 to 0.434 with $7 \mathrm{Var}$, and a range from 0.628 to 0.452 with $7 \mathrm{Var}+$ $\mathrm{ADI}+\mathrm{TJA}+T_{c}$ for the q10, q50, and q100 quantiles. The RMSE values and the rRMSE values of 7Var range from 0.071 to 0.261 and range from 186.77 to 202.34 , whereas the RMSE values and rRMSE of 7Var $+\mathrm{ADI}+\mathrm{TJA}+T_{c}$ range from 0.062 to 0.253 and range from 99.92 to 135.62 for the three quantiles. Further, The MAE values and the rBIAS values of 7 Var range from 0.017 to 0.054 and range from -62.10 to -62.58 , whereas the MAE values and rBIAS of $7 \mathrm{Var}+\mathrm{ADI}+$ TJA $+T_{c}$ range from 0.010 to 0.043 and range from -24.95 to -41.97 for the $\mathrm{q} 10, \mathrm{q} 50$, and $\mathrm{q} 100$ quantiles. The relative statistical indices of $7 \mathrm{Var}+\mathrm{ADI}+\mathrm{TJA}+T_{c}$ clearly show superior performance compared with the indices of Var7. In practical hydrology, a change of even $1 \%$ in the estimation of a design quantile for a dam could translate into a cost difference of tens of millions of dollars.

\section{c. River network classification}

River network classification data are used in RFA to define homogenous regions in arid and semiarid regions. Different drainage network types are associated with different hydrological responses. Therefore, we expect that the use of information on drainage network types could improve homogenous group delineation. In the present work, we identified different river network types using the power-law exponents proposed by Jung et al. (2015) for the channel network classification of 105 river networks. Among these, 49 were dendritic, 36 were pinnate, and 20 were trellis networks. These classified river networks were used to define homogenous regions in our study.

\section{d. Models with river network classification using tenfold cross validation}

Forty-nine dendritic networks were identified in the 105 drainage networks. Figure 6 shows the plot of the RMSE values of the EANN-CCA model using 7Var $+\mathrm{ADI}+\mathrm{TJA}+T_{c}$ as a 

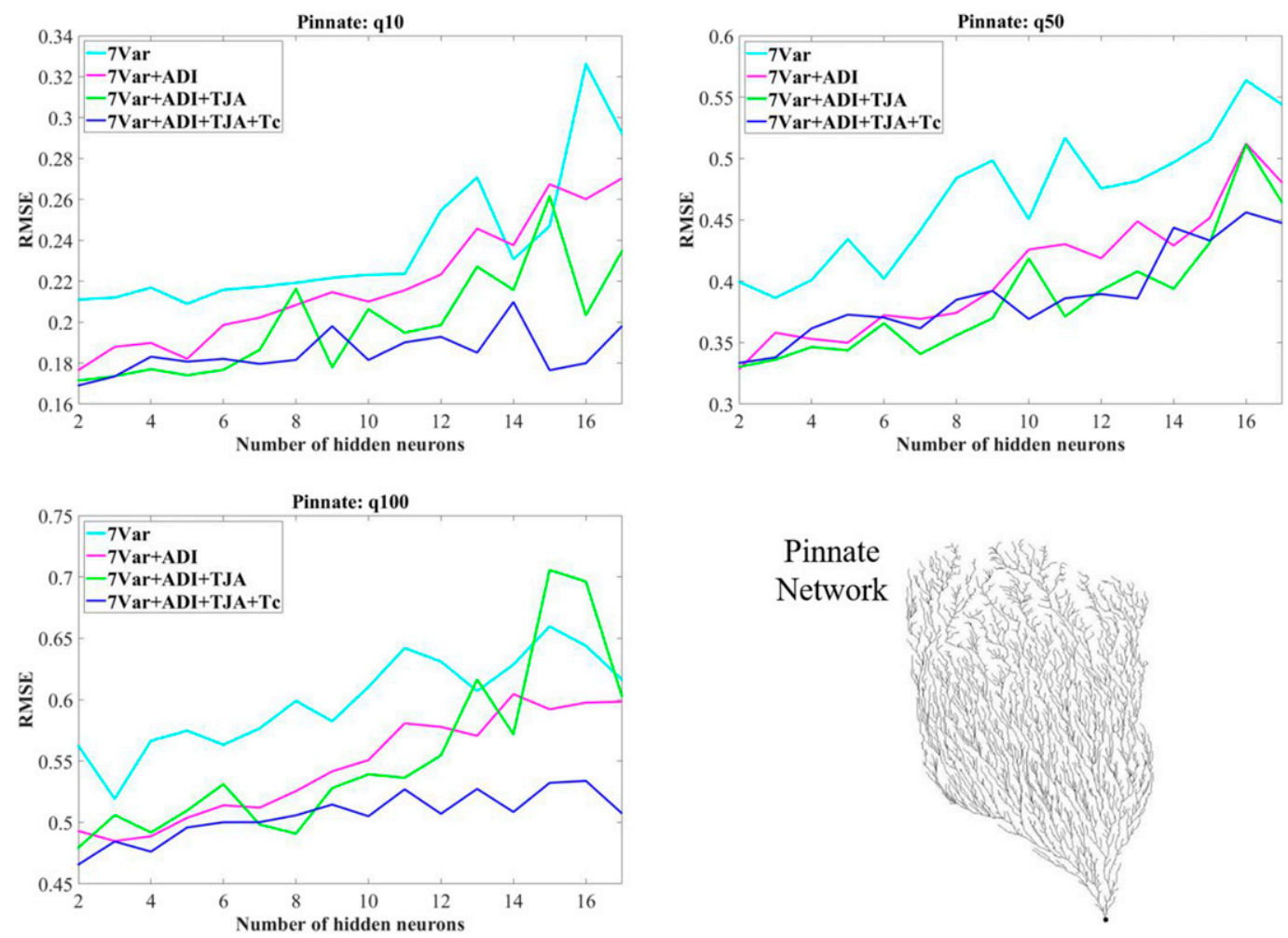

FIG. 7. RMSE of the EANN-CCA model for pinnate networks using the cross-validation method for four case studies (7Var, 7Var + ADI, 7Var + ADI + TJA, 7Var + ADI + TJA + $T_{c}$ ) for the three quantiles with a number of hidden neurons increasing from 2 to 17.

function of the number of hidden neurons, ranging from 2 to 17 , for the three quantiles of the dendritic networks.

Figure 6 indicates that the model performance improved when ADI, TJA, and $T_{c}$ are added to the 7 Var variables for quantile $q 10$. However, the models using 7Var + ADI + TJA and $7 \mathrm{Var}+\mathrm{ADI}+\mathrm{TJA}+T_{c}$ show similar RMSE values for quantiles q50 and q100. The EANN-CCA model with 7Var shows large RMSE fluctuations, as using 7Var alone with a small number of stations is not sufficient to produce stable results for the RFA procedure.

Among the 105 river networks, 36 drainage networks were identified as pinnate networks. Figure 7 shows the RMSE values of models using four variable combinations to assess model performance in these networks. The performance of the 7Var + ADI model was superior to that of the model using 7 Var. However, adding the TJA and $T_{c}$ variables to the models led to only minor improvements for the estimates in each quantile. Figure 7 also shows that the proposed models appeared to suffer from overfitting owing to insufficient training cases for large numbers of hidden neurons.

Twenty trellis river networks were identified among the 105 drainage networks. Figure 8 shows the RMSE values for models with different numbers of hidden neurons in trellis networks. There was no significant improvement when we used the models with 7Var + ADI and 7Var + ADI + TJA compared with the model with 7Var. The performance of the model using $7 \mathrm{Var}+\mathrm{ADI}+\mathrm{TJA}+T_{c}$ is superior to that of the model based on 7Var. Substantial fluctuation is also observed for the models using 7Var, 7Var + ADI, and 7Var + ADI + TJA with several hidden neurons. This could be ascribed to the small number of stations, which affects the accuracy of the RFA procedures.

\section{e. Models with classification versus models without classification}

In this section, we discuss the effectiveness of using drainage network types (dendritic, pinnate, and trellis) in defining homogenous regions to derive flood quantile estimates. For this purpose, we conducted RFA using the EANN-CCA model with 7Var $+\mathrm{ADI}+\mathrm{TJA}+T_{c}$. To determine whether the river network type classifications improved model performance through the improved delineation of homogenous regions, we examined models based on classified versus unclassified river networks. For the model with unclassified channel networks that were not defined as homogenous regions, 49, 36, and 20 drainage networks indicating the number of dendritic, pinnate, and trellis networks, respectively, were selected randomly from the 105 channel networks. Figure 9 shows the RMSE values for groups 49, 36, and 20 river networks for quantiles q10, q50, and q100, respectively. The figure shows the results obtained from the analysis with river network classification, in which homogenous regions were delineated, and the results of the analysis without river network classification, with homogenous regions not delineated. 

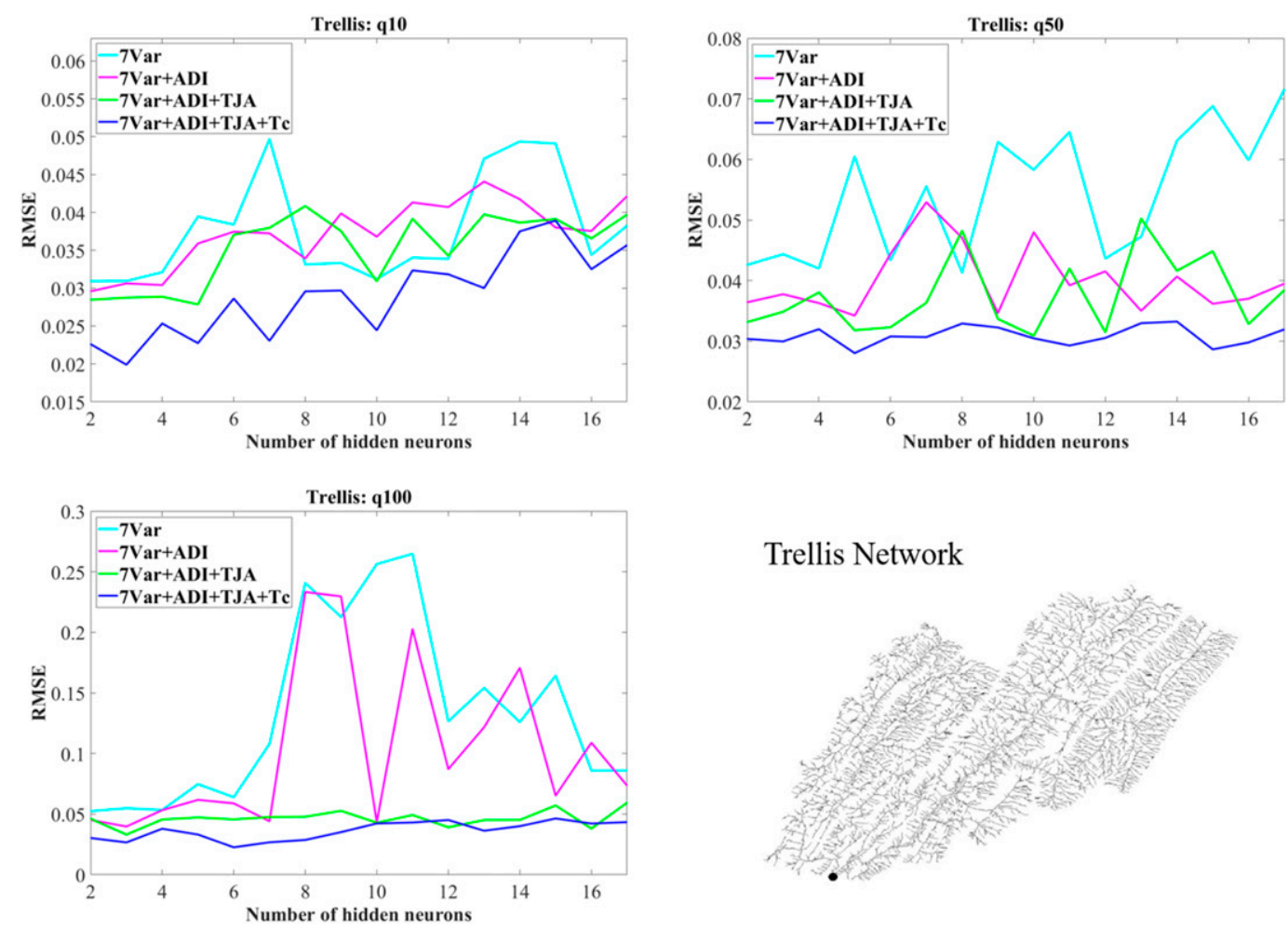

FIG. 8. RMSE of the EANN-CCA model for trellis networks using the cross-validation method for four case studies (7Var, 7Var + ADI, 7Var + ADI + TJA, 7Var + ADI + TJA $+T_{c}$ ) for the three quantiles with a number of hidden neurons increasing from 2 to 17.

Figure 9 shows that the results for dendritic and trellis networks based on river network classification are superior to those obtained without river network classification for the three quantiles. The results corresponding to trellis networks show a particularly significant improvement in association with the use of drainage network classification. However, opposite results are shown for pinnate networks, i.e., the performance of models without river network classification was superior to those with river network classification. This could be ascribed to the characteristics of pinnate networks being more complex compared with those of other network types. This aspect would need to be investigated in future work. Further, the development and feature of pinnate networks are not clear. Several authors have attempted to identify the differences between other
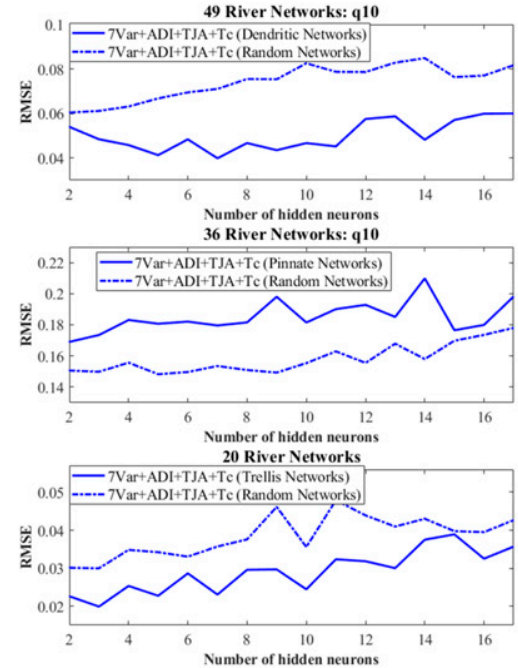
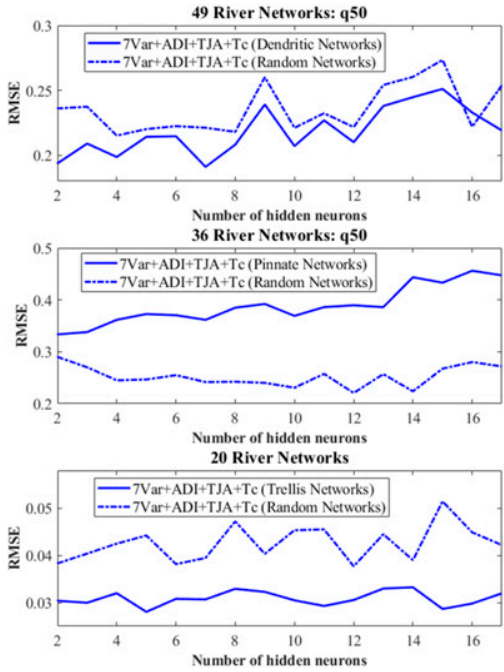
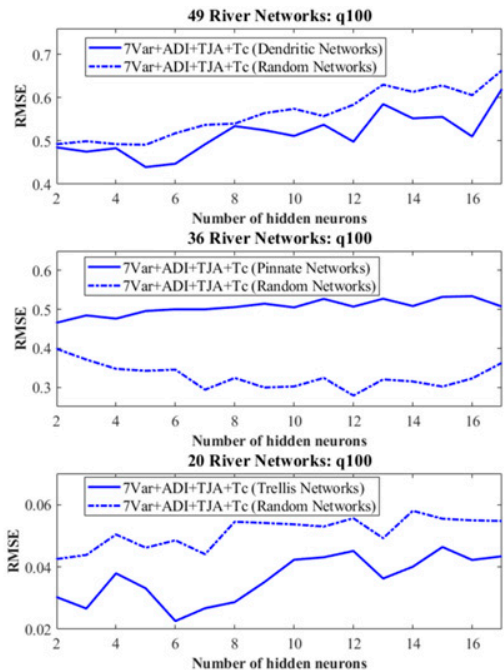

FIG. 9. RMSE of the EANN-CCA model using the cross-validation method for the classified networks and for the random networks based on $7 \mathrm{Var}+\mathrm{ADI}+\mathrm{TJA}+T_{c}$ with the three quantiles changing a number of hidden neurons from 2 to 17. 
TABLE 3. Results based on the 7Var + ADI + TJA $+T_{c}$ model with q10, q50, and q100 quantiles for consideration of river network classification including the dendritic network, pinnate network, and trellis network. The bold font indicates the best-performing approach for each quantile.

\begin{tabular}{|c|c|c|c|c|c|c|}
\hline & \multicolumn{2}{|c|}{ q10 } & \multicolumn{2}{|c|}{ q50 } & \multicolumn{2}{|c|}{ q100 } \\
\hline & Unclassified & Dendritic & Unclassified & Dendritic & Unclassified & Dendritic \\
\hline NSE & 0.511 & 0.648 & 0.481 & 0.557 & 0.474 & 0.493 \\
\hline RMSE & 0.074 & 0.050 & 0.236 & 0.219 & 0.562 & 0.516 \\
\hline rRMSE (\%) & 123.837 & 86.305 & 189.260 & 139.712 & 310.780 & 185.099 \\
\hline MAE & 0.005 & 0.004 & 0.053 & 0.042 & 0.162 & 0.105 \\
\hline \multirow[t]{2}{*}{ rBIAS (\%) } & -51.103 & -31.244 & -82.767 & -64.573 & -153.376 & -86.526 \\
\hline & Unclassified & Pinnate & Unclassified & Pinnate & Unclassified & Pinnate \\
\hline NSE & 0.601 & 0.589 & 0.577 & 0.594 & 0.515 & 0.548 \\
\hline RMSE & 0.158 & 0.185 & 0.253 & 0.389 & 0.328 & 0.506 \\
\hline rRMSE (\%) & 67.403 & 120.927 & 83.705 & 105.390 & 104.397 & 82.675 \\
\hline MAE & 0.055 & 0.068 & 0.082 & 0.167 & 0.108 & 0.209 \\
\hline \multirow[t]{2}{*}{ rBIAS (\%) } & -19.436 & -45.881 & -22.342 & -34.187 & -33.806 & -21.390 \\
\hline & Unclassified & Trellis & Unclassified & Trellis & Unclassified & Trellis \\
\hline NSE & 0.501 & 0.585 & 0.472 & 0.602 & 0.374 & 0.527 \\
\hline RMSE & 0.038 & 0.029 & 0.043 & 0.031 & 0.051 & 0.036 \\
\hline rRMSE (\%) & 66.370 & 39.635 & 144.444 & 31.962 & 151.153 & 30.282 \\
\hline MAE & 0.007 & 0.011 & 0.013 & 0.009 & 0.010 & 0.003 \\
\hline rBIAS (\%) & -19.871 & -12.348 & -38.756 & -5.456 & -79.984 & -6.280 \\
\hline
\end{tabular}

networks and pinnate networks; however, this is beyond the scope of the present study (Phillips and Schumm 1987; Mejia and Niemann 2008; Jung et al. 2011; Jung and Ouarda 2015). In these studies, the regional slopes of rivers or surface characteristics, such as sandy loams, clay loams, and erodible surfaces, were shown to affect river network classifications. In addition, combining variables, such as the arid index and tributary junction angle, proposed in the study for RFA at arid and semiarid regions could affect the performances of the models with and without classification. Other geomorphological features that differ between the different river networks and the effect of these features on hydrological models should be considered in detail in the future.

Table 3 shows the statistical indices, NSE, RMSE, rRMSE, MAE, and rBIAS for the model with 7Var $+\mathrm{ADI}+\mathrm{TJA}+T_{c}$. As shown in the table, we compared the results for the river networks without and with classification based on the q10, q50, and q100 quantiles. The classified networks for dendritic and trellis networks tend to produce superior performance with the indices compared with the unclassified networks for the three quantiles, as shown in Fig. 9. The networks classified as pinnate tend to show inferior performance compared with the unclassified networks, except for the q100 quantile with rRMSE and rBIAS. In the analysis of Jennings et al. 1994, various regional regression equations were used to estimate the frequency and magnitude of floods at ungauged locations in each state of the United States. These authors examined multivariate regional statistical relationships between stream, climate, and geomorphology to calculate flood-flow statistics. They also investigated typical approaches to streamflow prediction based on the delineation of geographical areas with similar patterns for flows at ungauged sites. Their results showed that the estimates of floods were reasonable and provided estimates similar to station data (Jennings et al. 1994). These typical regression equations and approaches should be considered for comparison with the proposed method in estimating hydrological variables in future work.

\section{Conclusions}

In the present study, we proposed using river network information related to the dynamics of river basins to improve the performance of RFA models. The analysis involved 105 river basins in arid and semiarid regions of the United States. For the structure of the model, the CCA approach and an ANN ensemble method were applied for estimation of the flood quantiles (q10, q50, and q100). Based on the EANN-CCA model, we determined whether the physiographical and meteorological variables, including ADI, TJA, $T_{c}$, and $3 \mathrm{EXP}$, affected the model performance. Further, we used river network classification to enhance flood quantile estimates by defining homogenous regions.

Tenfold cross- and jackknife validation techniques were used as resampling approaches to evaluate the performance of EANN-CCA models employing different combinations of variables (7Var, ADI, TJA, $T_{c}$, and 3EXP). Among several combinations we used, the model with variables 7Var + ADI + TJA $+T_{c}$ produced a superior performance in estimating the three quantiles. The performance of the model with the proposed variables was superior compared with a model with 7Var. The performance of the model using 7Var + ADI + TJA + $T_{c}$, was enhanced gradually by adding the variables ADI, TJA, and $T_{c}$ to 7 Var. However, when we included 3EXP in 7Var $+\mathrm{ADI}+\mathrm{TJA}+T_{c}$, the model performed poorly. Some variables were not adequately representative of the hydrological processes. 
For the identification of the effect of river network classification in RFA, 49 of the 105 drainage networks were identified as dendritic, 36 as pinnate, and 20 as trellis. The various network types were used to define the homogenous regions. The performance of the model with 7Var $+\mathrm{ADI}+\mathrm{TJA}+T_{c}$ was assessed for each network type based on the RMSE values for the three flood quantiles. Adding the variables TJA and $T_{c}$ to the model using 7Var + ADI produced stable results. The model using homogenous regions defined through river network classification was compared with the model without homogenous regions. The results showed that the performance of the model with classification was superior compared with that of the model without classification for the dendritic and trellis networks. However, for pinnate networks, the model without classification appeared to produce superior performance.

Future studies should employ data from a larger number of river basins in arid and semiarid regions and other climates to study the value of river network information in various RFA procedures. Studies should also explore the use of physical data, such as geology and land use, to classify river basins. Future efforts could also focus on the use of river network classification in multivariate RFA procedures and in combination of local and regional analysis, i.e., where it is important to adequately delineate homogenous regions for the target site.

Acknowledgments. This research was supported by the Basic Science Research Program of the National Research Foundation of Korea (NRF), funded by the Ministry of Education (Grant 2019R1I1A1A01061109). There are no conflicts of interest to declare.

Data availability statement. The hydrological variables were obtained from the U.S. Geological Survey (https://www.usgs. gov/). For the physiographical variables, DEMs were obtained from the National Elevation Dataset (https://viewer.nationalmap. gov/basic/). The meteorological variables were acquired from the Parameter-Elevation Regressions on Independent Slopes Model (http://www.prism.oregonstate.edu/). The data supporting the findings of this study are available from the corresponding author on reasonable request.

\section{REFERENCES}

Abdi, A., Y. Hassanzadeh, and T. B. M. J. Ouarda, 2017a: Regional frequency analysis using Growing Neural Gas network. J. Hydrol., 550, 92-102, https://doi.org/10.1016/ j.jhydrol.2017.04.047.

_ _ S. Talatahari, A. Fakheri-Fard, R. Mirabbasi, and T. B. M. J. Ouarda, 2017b: Multivariate regional frequency analysis: Two new methods to increase the accuracy of measures. Adv. Water Resour., 107, 290-300, https://doi.org/ 10.1016/j.advwatres.2017.07.006.

Abrahams, A. D., and J. J. Flint, 1983: Geological controls on the topological properties of some trellis channel networks. Geol. Soc. Amer. Bull., 94, 80-91, https://doi.org/10.1130/ 0016-7606(1983)94<80:GCOTTP>2.0.CO;2.

Alobaidi, M. H., P. R. Marpu, T. B. M. J. Ouarda, and F. Chebana, 2015: Regional frequency analysis at ungauged sites using a two-stage resampling generalized ensemble framework. Adv. Water Resour., 84, 103-111, https://doi.org/ 10.1016/j.advwatres.2015.07.019.

Argialas, D., J. Lyon, and O. Mintzer, 1988: Quantitative description and classification of drainage patterns. Photogramm. Eng. Remote Sens., 54, 505-509.

Aziz, K., A. Rahman, G. Fang, and S. Shrestha, 2014: Application of artificial neural networks in regional flood frequency analysis: A case study for Australia. Stochastic Environ. Res. Risk Assess., 28, 541-554, https://doi.org/10.1007/s00477-013-0771-5.

Beable, M. E., and A. I. McKerchar, 1982: Regional flood estimation in New Zealand. Water and Soil Tech. Publ. 20, 139 pp.

Besaw, L., D. M. Rizzo, P. R. Bierman, and W. R. Hackett, 2010: Advances in ungauged streamflow prediction using artificial neural networks. J. Hydrol., 386, 27-37, https://doi.org/ 10.1016/j.jhydrol.2010.02.037.

Burbank, D. W., 1992: Causes of recent Himalayan uplift deduced from deposited patterns in the Ganges basin. Nature, 357, 680-683, https://doi.org/10.1038/357680a0.

Cannon, A. J., and P. H. Whitfield, 2002: Downscaling recent streamflow conditions in British Columbia, Canada using ensemble neural network models. J. Hydrol., 259, 136-151, https://doi.org/10.1016/S0022-1694(01)00581-9.

Castellarin, A., D. H. Burn, and A. Brath, 2001: Assessing the effectiveness of hydrological similarity measures for flood frequency analysis. J. Hydrol., 241, 270-285, https://doi.org/ 10.1016/S0022-1694(00)00383-8.

Chebana, F., and T. B. M. J. Ouarda, 2007: Multivariate L-moment homogeneity test. Water Resour. Res., 43, W08406, https:// doi.org/10.1029/2006WR005639.

$\longrightarrow$, and - 2008: Depth and homogeneity in regional flood frequency analysis. Water Resour. Res., 44, W11422, https:// doi.org/10.1029/2007WR006771.

— quency analysis. Water Resour. Res., 45, W10435, https:// doi.org/10.1029/2008WR007490.

Chokmani, K., T. B. M. J. Ouarda, S. Hamilton, M. H. Ghedira, and H. Gingras, 2008: Comparison of ice-affected streamflow estimates computed using artificial neural networks and multiple regression techniques. J. Hydrol., 349, 383-396, https://doi.org/ 10.1016/j.jhydrol.2007.11.024.

Cox, K. G., 1989: The role of mantle plumes in the development of continental drainage patterns. Nature, 342, 873-877, https:// doi.org/10.1038/342873a0.

Dalrymple, T., 1960: Flood-frequency analyses. Manual of Hydrology: Part 3. Flood-flow techniques, USGS Water-Supply Paper 1543-A, 80 pp., https://pubs.usgs.gov/wsp/1543a/report.pdf.

Daniel, J., 1981: Drainage density as an index of climatic geomorphology. J. Hydrol., 50, 147-154, https://doi.org/10.1016/ 0022-1694(81)90065-2.

Daniell, T. M., 1991: Neural network: Application in hydrology and water resources engineering. Int. Hydrology Water Resources Symp., Perth, Australia, Institute of Engineers, 797-802.

Dawson, C. W., and R. L. Wilby, 2001: Hydrological modelling using artificial neural networks. Prog. Phys. Geogr., 25, 80-108, https://doi.org/10.1177/030913330102500104.

— , R. J. Abrahart, A. Y. Shamseldin, and R. L. Wilby, 2006: Flood estimation at ungauged sites using artificial neural networks. J. Hydrol., 319, 391-409, https://doi.org/10.1016/ j.jhydrol.2005.07.032.

Dietterich, T. G., 1997: Machine-learning research. AI Mag., 18 (4), 97, https://doi.org/10.1609/aimag.v18i4.1324.

Durocher, M., F. Chebana, and T. B. M. J. Ouarda, 2016: Delineation of homogenous regions using hydrological 
variables predicted by projection pursuit regression. Hydrol. Earth Syst. Sci., 20, 4717-4729, https://doi.org/10.5194/hess-204717-2016.

Durrans, S. R., and S. Tomic, 1996: Regionalization of low-flow frequency estimates: An Alabama case study. J. Amer. Water Resour. Assoc., 32, 23-37, https://doi.org/10.1111/ j.1752-1688.1996.tb03431.x.

Faridzad, M., T. Yang, K. Hsu, S. Sorooshian, and C. Xiao, 2018: Rainfall frequency analysis for ungauged regions using remotely sensed precipitation information. J. Hydrol., 563, 123-142, https://doi.org/10.1016/j.jhydrol.2018.05.071.

Farquharson, F. A. K., J. R. Meigh, and J. V. Sutcliffe, 1992: Regional flood frequency analysis in arid and semi-arid areas. J. Hydrol., 138, 487-501, https://doi.org/10.1016/0022-1694(92) 90132-F.

Flavell, D., 1983: Design flood estimation in Western Australia. Waterway Analysis and Design: NAASRA BEC 1983 Seminar, Adelaide, South Australia, Australia, National Association of Australian State Road Authorities, 23 pp.

Folmar, N. D., and A. C. Miller, 2000: Historical perspective of the NRCS lag time equation. Transportation Research Board 70th Annual Meeting, Washington, DC, Transportation Research Board.

Gloaguen, R., P. R. Marpu, and I. Niemeyer, 2007: Automatic extraction of faults and fractal analysis from remote sensing data. Nonlinear Processes Geophys., 14, 131-138, https:// doi.org/10.5194/npg-14-131-2007.

Gonzalez, R., T. B. M. J. Ouarda, P. R. Marpu, M. M. Allam, E. A. B. Eltahir, and S. Pearson, 2016: Water budget analysis in arid regions, application to the United Arab Emirates. Water, 8, 415, https://doi.org/10.3390/w8090415.

Govindaraju, R. S., 2000: Artificial neural networks in hydrology II. Hydrological applications. J. Hydrol. Eng., 5, 124-137, https:// doi.org/10.1061/(ASCE)1084-0699(2000)5:2(124).

Grover, P. L., D. H. Burn, and J. M. Cunderlik, 2002: A comparison of index flood estimation procedures for ungauged catchments. Can. J. Civ. Eng., 29, 734-741, https://doi.org/10.1139/102-065.

Hackney, C., and P. Carling, 2011: The occurrence of obtuse junction angles and changes in channel width below tributaries along the Mekong River, south-east Asia. Earth Surf. Processes Landforms, 36, 1563-1576, https://doi.org/10.1002/esp.2165.

Haddad, K., and A. Rahman, 2012: Regional flood frequency analysis in eastern Australia: Bayesian GLS regression-based methods within fixed region and ROI framework-Quantile Regression vs. Parameter Regression Technique. J. Hydrol., 430-431, 142-161, https://doi.org/10.1016/j.jhydrol.2012.02.012.

Hagan, M. T., and M. B. Menhaj, 1994: Training feedforward networks with the Marquardt algorithm. IEEE Trans. Neural Netw., 5, 989-993, https://doi.org/10.1109/72.329697.

Hamon, W. R., 1960: Estimating potential evapotranspiration. B.S. thesis, Massachusetts Institute of Technology, $75 \mathrm{pp}$.

Horton, R. E., 1945: Erosional development of streams and their drainage basins; hydrophysical approach to quantitative morphology. Geol. Soc. Amer. Bull., 56, 275-370, https://doi.org/ 10.1130/0016-7606(1945)56[275:EDOSAT]2.0.CO;2.

Hosking, J., and J. R. Wallis, 1993: Some statistics useful in regional frequency analysis. Water Resour. Res., 29, 271-281, https:// doi.org/10.1029/92WR01980.

— Based on L-Moments. Cambridge University Press, 242 pp.

Howard, A. D., 1967: Drainage analysis in geologic interpretation: A summation. Amer. Assoc. Pet. Geol. Bull., 51, 2246-2259, https:// doi.org/10.1306/5D25C26D-16C1-11D7-8645000102C1865D.
Hua, J., Z. Liang, and Z. Yu, 2003: A modified rational formula for flood design in small basins. J. Amer. Water Resour. Assoc., 39, 1017-1025, https://doi.org/10.1111/j.1752-1688. 2003.tb03689.x.

Ichoku, C., and J. Chorowicz, 1994: A numerical approach to the analysis and classification of channel network patterns. Water Resour. Res., 30, 161-174, https://doi.org/10.1029/93WR02279.

Jennings, M. E., W. O. Thomas Jr., and H. C. Riggs, 1994: Nationwide summary of U.S. Geological Survey regional regression equations for estimating magnitude and frequency of floods for ungaged sites, 1993. USGS Water-Resources Investigations Rep. 94-4002, 196 pp., https://doi.org/10.3133/wri944002.

Jung, K., and T. B. M. J. Ouarda, 2015: Analysis and classification of channel network types for intermittent streams in the United Arab Emirates and Oman. J. Civil Environ. Eng., 5, 1000183, https://doi.org/10.4172/2165-784X.1000183.

_ J. D. Niemann, and X. Huang, 2011: Under what conditions do parallel river networks occur? Geomorphology, 132, 260271, https://doi.org/10.1016/j.geomorph.2011.05.014.

_, P. R. Marpu, and T. B. M. J. Ouarda, 2015: Improved classification of drainage networks using junction angles and secondary tributary lengths. Geomorphology, 239, 41-47, https://doi.org/10.1016/j.geomorph.2015.03.004.

,-- , and -2017 : Impact of river network type on the time of concentration. Arab. J. Geosci., 10, 546, https://doi.org/ 10.1007/s12517-017-3323-3.

_ Korean river basins using a Canonical Correlation Analysis and Neural Network (CCA-NN) based regional frequency analysis. Atmosphere, 10, 695, https://doi.org/10.3390/atmos10110695.

Kendall, M. G., 1948: Rank Correlation Methods. Charles Griffin, $160 \mathrm{pp}$.

Kjeldsen, T. R., and D. A. Jones, 2010: Predicting the index flood in ungauged UK catchments: On the link between data-transfer and spatial model error structure. J. Hydrol., 387, 1-9, https:// doi.org/10.1016/j.jhydrol.2010.03.024.

Luk, K. C., J. E. Ball, and A. Sharma, 2001: An application of artificial neural networks for rainfall forecasting. Math. Comput. Modell., 33, 683-693, https://doi.org/10.1016/S0895-7177(00) 00272-7.

Maliva, R., and T. Missimer, 2012: Aridity and drought. Arid Lands Water Evaluation and Management. Springer, 21-39.

Matalas, N. C., J. R. Slack, and J. R. Wallis, 1975: Regional skew in search of a parent. Water Resour. Res., 11, 815-826, https:// doi.org/10.1029/WR011i006p00815.

Mejia, A. I., and J. D. Niemann, 2008: Identification and characterization of dendritic, parallel, pinnate, rectangular, and trellis networks based on deviations from planform selfsimilarity. J. Geophys. Res., 113, F02015, https://doi.org/ 10.1029/2007JF000781.

Miller, R. G., 1964: A trustworthy jackknife. Ann. Math. Stat., 35, 1594-1605, https://doi.org/10.1214/aoms/1177700384.

Mosaffaie, J., 2015: Comparison of two methods of regional flood frequency analysis by using L-moments. Water Res., 42, 313-321, https://doi.org/10.1134/S0097807815030112.

Mosley, M. P., 1972: An experimental study of rill erosion. M.S. thesis, Colorado State University, 118 pp.

Muttiah, R. S., R. Srinivasan, and P. M. Allen, 1997: Prediction of two year peak stream discharges using neural networks. J. Amer. Water Resour. Assoc., 33, 625-630, https://doi.org/ 10.1111/j.1752-1688.1997.tb03537.x.

Ouarda, T. B. M. J., and C. Shu, 2009: Regional low-flow frequency analysis using single and ensemble artificial neural 
networks. Water Resour. Res., 45, W11428, https://doi.org/ 10.1029/2008WR007196.

_, C. Girard, G. S. Cavadias, and B. Bobée, 2001: Regional flood frequency estimation with canonical correlation analysis. J. Hydrol., 254, 157-173, https://doi.org/10.1016/S00221694(01)00488-7.

— C. Charron, and A. St-Hilaire, 2008: Statistical models and the estimation of low flows. Can. Water Resour. J., 33, 195-206, https://doi.org/10.4296/cwrj3302195.

,,-- Y. Hundecha, A. St-Hilaire, and F. Chebana, 2018: Introduction of the GAM model for regional low-flow frequency analysis at ungauged basins and comparison with commonly used approaches. Environ. Modell. Software, 109, 256-271, https://doi.org/10.1016/j.envsoft.2018.08.031.

Pallard, B., A. Castellarin, and A. Montanari, 2009: A look at the links between drainage density and flood statistics. Hydrol. Earth Syst. Sci., 13, 1019-1029, https://doi.org/ 10.5194/hess-13-1019-2009.

Pandey, G. R., and V. T. V. Nguyen, 1999: A comparative study of regression based methods in regional flood frequency analysis. J. Hydrol., 225, 92-101, https://doi.org/10.1016/S0022-1694(99) 00135-3.

Parvis, M., 1950: Drainage pattern significance in airphoto identification of soils and bedrocks. Photogramm. Eng., 16, 375-409.

Phillips, L. F., and S. Schumm, 1987: Effect of regional slope on drainage networks. Geology, 15, 813-816, https://doi.org/ 10.1130/0091-7613(1987)15<813:EORSOD>2.0.CO;2.

Rahman, A., C. Charron, T. B. M. J. Ouarda, and F. Chebana, 2018: Development of regional flood frequency analysis techniques using generalized additive models for Australia. Stochastic Environ. Res. Risk Assess., 32, 123-139, https:// doi.org/10.1007/s00477-017-1384-1.

Requena, A. I., T. B. M. J. Ouarda, and F. Chebana, 2017: Flood frequency analysis at ungauged sites based on regionally estimated streamflows. J. Hydrometeor., 18, 2521-2539, https:// doi.org/10.1175/JHM-D-16-0143.1.

,-- , and -2018 : Low-flow frequency analysis at ungauged sites based on regionally estimated streamflows. J. Hydrol., 563, 523-532, https://doi.org/10.1016/j.jhydrol.2018.06.016.

Seidou, O., T. B. M. J. Ouarda, M. Barbet, P. Bruneau, and B. Bobée, 2006: A parametric Bayesian combination of local and regional information in flood frequency analysis. Water Resour. Res., 42, W11408, https://doi.org/10.1029/2005WR004397.
Shao, J., and D. Tu, 2012: The Jackknife and Bootstrap. Springer Science \& Business Media, 517 pp.

Sharifi, S., and S. M. Hosseini, 2011: Methodology for identifying the best equations for estimating the time of concentration of watersheds in a particular region. J. Irrig. Drain. Eng., 137, 712-719, https://doi.org/10.1061/(ASCE) IR.1943-4774.0000373.

Shu, C., and D. H. Burn, 2004: Artificial neural network ensembles and their application in pooled flood frequency analysis. Water Resour. Res., 40, W09301, https://doi.org/10.1029/2003WR002816. , and T. B. M. J. Ouarda, 2007: Flood frequency analysis at ungauged sites using artificial neural networks in canonical correlation analysis physiographic space. Water Resour. Res., 43, W07438, https://doi.org/10.1029/2006WR005142.

Stadler, S. J., 1987: Aridity indexes. Climatology. Springer, 102-107.

Turan, M. E., and M. A. Yurdusev, 2009: River flow estimation from upstream flow records by artificial intelligence methods. J. Hydrol., 369, 71-77, https://doi.org/10.1016/ j.jhydrol.2009.02.004.

Velde, B., J. Dubois, G. Touchard, and A. Badri, 1990: Fractal analysis of fractures in rocks: The Cantor's dust method. Tectonophysics, 179, 345-352, https://doi.org/10.1016/0040-1951(90)90300-W.

Wald, A., and J. Wolfowitz, 1943: An exact test for randomness in the non-parametric case based on serial correlation. Ann. Math. Stat., 14, 378-388, https://doi.org/10.1214/aoms/1177731358.

Walton, K., 1969: The Arid Zones. Aldine Publishing Co., 175 pp.

Ward, J. H., 1963: Hierarchical grouping to optimize an objective function. J. Amer. Stat. Assoc., 58, 236-244, https://doi.org/ 10.1080/01621459.1963.10500845.

Wazneh, H., F. Chebana, and T. B. M. J. Ouarda, 2016: Identification of hydrological neighborhoods for regional flood frequency analysis using statistical depth function. Adv. Water Resour., 94, 251-263, https://doi.org/10.1016/ j.advwatres.2016.05.013.

Wilcoxon, F., 1945: Individual comparisons by ranking methods. Biom. Bull., 1, 80-83, https://doi.org/10.2307/3001968.

Wong, T. S., 2005: Assessment of time of concentration formulas for overland flow. J. Irrig. Drain. Eng., 131, 383-387, https:// doi.org/10.1061/(ASCE)0733-9437(2005)131:4(383).

Zaman, M. A., A. Rahman, and K. Haddad, 2012: Regional flood frequency analysis in arid regions: A case study for Australia. J. Hydrol., 475, 74-83, https://doi.org/10.1016/ j.jhydrol.2012.08.054. 